\title{
O "POPULAR" NO FUTEBOL DO INTERIOR DE SÃO PAULO
}

Dr. José Luiz dos Anjos

Universidade Federal do Espírito Santo

\section{Resumo}

O estudo trata da fundação e formação de clubes do interior de São Paulo, limitando sua análise na A. A. Ponte Preta, de Campinas e E. C. XV de Novembro, de Piracicaba. Traduz a organização dos trabalhadores na formação dos clubes do interior, a construção de símbolos e a administração dos clubes, configurando a visão típica dos clubes do interior do Estado ainda presente no futebol contemporâneo. Aponta as relações de interesses entre dirigentes dos clubes do interior paulista com os clubes da Capital. Considera que a manutenção dos clubes do interior deve-se ao fato da continuidade das relações que promovem os enredamentos sociais e que historicamente, a formação dos clubes se deu na organização de diversos extratos sociais e étnicos.

Palavras Chave: Futebol paulista; Organização; Relações sociais.

Buscando nos registros históricos, propusemos-nos a abordar a formação de clubes de futebol e as relações sociais que apontaram um cenário diferente dos grandes centros urbanos, precisamente Rio de Janeiro e São Paulo. A ampliação das novas relações sociais nas cidades do início do século XX fez com que muitas levas de migrantes se apropriassem de novos estilos de vida, que marcaram distinções e possibilitaram a criação de novos valores. Nesse processo, podia-se identificar muitos de seus regionalismos, de suas culturas e de suas resistências culturais, enfim, do cotidiano popular que fora transplantado para a vida urbana. Também o futebol, de maneira muito clara, foi palco desse cenário.

A maioria dos estudos e da produção bibliográfica concentra suas incursões nos fatos procedentes do eixo Rio - São Paulo. Sem desmerecer tais estudos e análises, fizemos opção por uma mudança de cenário. Procuramos realizar um breve recorte tendo como escopo o futebol no Interior do Estão de São Paulo, mais precisamente na região de Campinas onde, desde as décadas iniciais do século XX, é possível identificar o futebol criando e promovendo relações na Capital e no interior do Estado.

Os objetivos não contemplam uma discussão exaustiva de todos os aspectos deste cenário. Devemos procurar entender como foram tratados e vistos alguns fenômenos sociais e culturais e como se deu sua transposição para o futebol. As 
considerações, nesse sentido, procuram estabelecer relações com o início da popularidade do futebol no Brasil, tendo o começo do século XX como foco de análise.

Trataremos da entrada das camadas populares no futebol, detendo-nos nos clubes de formação operária/trabalhadora e clubes formados a partir dos interesses mútuos dos extratos médios sociais que procuravam se constituir socialmente. ${ }^{1}$

Delimitado o nosso objetivo, elegemos dois clubes que, embora semelhantes na sua formação, apresentam características distintas.

Temos o estudo de equipes do interior do Estado de São Paulo, entre elas, a Associação Atlética Ponte Preta de Campinas, o E. C. XV de Novembro de Piracicaba. Essas equipes, possuem em sua gênese, faces populares, traduzindo-se na estética que hoje apresentam. De outra forma, analisar essas equipes suscita novos olhares aos estudos do futebol, que gira em torno do eixo Rio - São Paulo, resumindo-se nas equipes de ambas as Capitais; no caso do Rio de Janeiro, os estudos recaem em exaustivas análises da obra de Mario Filho, O Negro no futebol brasileiro $(1947 ; 1964)$.

O conceito "popular" aqui empregado compreende os grupos dissidentes que negavam uma maior liberdade dos associados em clubes associativos e recreativos ou que propunham formas diferentes de administrar a associação criada. Esses grupos podem ser chamados de "rebeldes" pois se apartaram de sua sociedade para criar ou fundar uma nova associação. Falando do interior de São Paulo, "popular” foram os clubes que, constituídos por pessoas pertencentes às diversas classes trabalhadoras, fundaram clubes associativos, tendo entre características o lazer de final de semana e a prática do esporte, preferencialmente, o futebol. Nota-se que esses grupos não eram homogêneos, pois se constituíam de pessoas pertencentes a diversas classes de trabalhadores. Entre essas diferenças, alguma semelhança pode ser identificada na história desses grupos formadores e fundadores dos primeiros clubes no interior de São Paulo: o fortalecimento de um time para enfrentar um arqui-rival ou a união de duas ou

\footnotetext{
${ }^{1}$ A bibliografia sobre o futebol brasileiro tem priorizado o eixo Rio - São Paulo, não traduzindo outros contextos regionais. Em nossa pesquisa, pudemos identificar que a entrada das camadas populares (trabalhadora) no futebol, no início do século XX, contém contornos regionalmente diferentes. Em São Paulo, o futebol trouxe a distinção de classe e serviu de lazer para as classes trabalhadoras e, no Rio Grande do Sul, foi ato de resistência contra a opressão e discriminação, como a Liga das canelas pretas.
} 
mais equipes para suprir as necessidades do futebol, como bolas, uniformes e sapatos próprios (chuteiras). Esses grupos estendem-se aos grupos ligados aos ferroviários, eletricitários, trabalhadores das Companhias de gás e, mesmo constituindo-se em clubes associativos, procuravam abrir para as mais distintas classes sociais.

Esse "popular" existente em diversos clubes brasileiros que indicava a democratização, a popularização do futebol logo no início do século XX, pode ser identificado no Clube de Regatas Vasco da Gama, fundando em 1898, clube carioca que foi pioneiro, logo em 1904, ao eleger o primeiro presidente não branco da história dos clubes cariocas em oposição ao Fluminense Football Club, que destaca, em sua história, a relação da aristocracia carioca no mundo do futebol. Fatos como esses podem ser vistos em Minas Gerais; entre Cruzeiro e Atlético Mineiro; em Pernambuco, entre Santa Cruz e Sport Recife; no Rio Grande do Sul, entre Grêmio e Internacional; e em São Paulo, em suas primeiras décadas, entre o Paulistano e o Corinthians Paulista, este último nascido no Bom Retiro. A popularidade dos clubes do interior de São Paulo se estende entre a oposição e as rivalidades existentes num mesmo município ou não muito distantes entre si. As cidades do interior de São Paulo, nas primeiras décadas do século XX, já tinham fôlego para constituir e suportar duas equipes e o trânsito social garantia inclusive a criação de ligas locais e regionais. Em Campinas, dois times de futebol com características sociais diferentes se opunham em seus trânsitos sociais e esportivos: o Guarani de Campinas, com seu público mais intelectualizado e gente jovem; e a Ponte Preta, constituída de bases populares, que, em 1912, liderou um movimento para a criação da Liga Operária de Footbaal Campineira, sendo um dos primeiros times de futebol constituído com sua administração nas bases populares. A aceitação de jogadores de diferentes estratos sociais e étnicos foi o motivo para ser apelidada de macaca, símbolo que conserva até hoje. ${ }^{2}$

\footnotetext{
${ }^{2}$ Há três versões sobre o apelido da Ponte Preta: antes da década de 20, quando a Ponte Preta admitiu muitos jogadores negros, daí ser chamada de macaca. A outra versão, data da década de 1950, quando o Maracanã foi inaugurado e, nesse mesmo ano, o Estádio Moisés Lucarelli recebia seu público para o jogo de estréia. Os torcedores do Guarani, chamavam o Estádio da Ponte Preta de Macacanã. A terceira versão narra que a origem do apelido, Macaca, veio da forma alegre e guerreira de como a torcida se comporta em campo.
} 
Autores têm se ocupado em historicizar o futebol no eixo Rio - São Paulo (de suas Capitais), deixando muitas lacunas ou mesmo deixando de mencionar o desenvolvimento do futebol no interior de São Paulo quanto às inserções de grupos sociais e as relações políticas com a sociedade na qual se organizou. Contudo, a força do futebol das equipes do interior não tem sido e não foi negligenciada pelos clubes da Capital, como se identifica em outros Estados brasileiros.

Ocorre que o futebol no interior de São Paulo desenvolveu-se tanto quanto o dos clubes da Capital, seja em números de clubes, seja em influência na sociedade em que penetrava - diferentemente do que ocorreu em outros Estados, nos quais o interior só chegou à elite do futebol em anos mais recentes, como na Bahia. A pujança do futebol do interior de São Paulo é retratada na data de fundação dos clubes e pela formação popular de diversos grupos de operários e trabalhadores, até hoje existentes. Podemos afirmar que houve necessidade da formação de clubes quer no interior, quer na Capital, pois, no desabrochar dos primeiros anos do século XX, a sociedade brasileira apontava a perspectiva do desenvolvimento industrial, mas que surgiria no decurso dos anos trinta com a política Pós-Vargas. Com a necessidade do lazer, tendo o Estado como precursor do discurso higienista, os diversos grupos étnicos passaram a se encontrar em seus redutos. Assim, não só clubes voltados ao futebol foram fundados, mas, na Capital Paulistana como no interior do Estado, os grupos étnicos fundaram suas agremiações. Entre essas na Capital apontamos: o Clube Pinheiros, de formação germânica (7/9/1899); Clube de Regatas Tietê de formação popular; Clube Espéria de formação italiana (1/11/1899), O Club Athetico Paulistano (29/12/1900) "fundado por uma genuína elite paulistana"; o C. A. Juventus, que pode ser considerado um time de fábrica, fundado em 1924 com influências de descendentes de italianos.

Pesquisando a fundação dos clubes paulistanos, nos documentos encontramos informações de que nem todos os clubes ofereciam a prática do futebol para seus associados. Os clubes que adotaram essa prática logo a deixaram, pois, embora não tenhamos documentos que registrem o fato, é possível refletir que o futebol oficial, no início do novo século XX, manifestava na sua prática a distinção social, porém, logo 
nos anos 20, isso deixa de ocorrer, tendo a classe operária dominado a prática corporal e técnica. ${ }^{3}$

A formação de clubes populares no interior de São Paulo possuiu configurações diferenciadas, devido à relação entre as diversas classes de trabalhadores que se estabeleciam nas pequenas cidades e constituíam em determinados espaços, como praças, igrejas e várzeas, o local próprio para gerar futuros enredos de laços pessoais e de interesse de grupos de trabalhadores. Assim, a fundação de clubes de futebol no interior de São Paulo não só foi motivada pelo ímpeto da organização e encontros dos trabalhadores como pela necessidade da continuidade do relacionamento familiar, pela troca equivalente de relações sociais e pelos aspectos sociais que se afloravam na época. Era nas festas e feiras agrícolas, no hipódromo e nos cafés que se encontravam a burguesia do interior e a classe popular, na várzea, nos campos de futebol.

A relação entre classes sociais motivadas pelo futebol no interior de São Paulo foi mais estreita se comparada com a Capital. A média burguesia do interior Bandeirante servia como elo entre as classes promovendo coesões de interesses, pois proprietárias de pequenas e médias áreas rurais de cana-de-acúcar e café, garantia a relação entre a classe rural trabalhadora e os detentores do poder localizados na urbanidade das cidades do interior paulista. Entre essas se encontram Bauru, Campinas, Limeira, Piracicaba, Ribeirão Preto etc. No interior de São Paulo o interesse se calcava na interação dos estratos sociais subalternos com os demais estratos sociais, garantindo assim uma pseudo-ascensão social. Se isso pode ser sentido no início do século XX, essa posição no futebol se manifestou com mais ênfase no decorrer dos anos de 1950, pelos presidentes dos clubes do interior. Apadrinhado por um diretor de algum clube de

${ }^{3} \mathrm{O}$ futebol oficial, conceituando aqui o futebol ligado a estrutura burocrática, no início do século XX, era de domínio dos clubes elitizados. Isso não implica que o futebol como prática corporal não estivesse sendo apropriado pela classe operária/trabalhadora. Os clubes elitizados vão perdendo essa característica no final dos anos 20 e o futebol, sendo popularizado, não se percebia a distinção social em seus praticantes. Buscando encontrar fontes para ratificar esses argumentos, recebemos documentos emitidos pelo Depto. de Comunicação do Paulistano, pelo qual [...] o motivo para o encerramento das atividades futebolísticas foi o fato de o futebol, já em 1929, ter o amadorismo marrom, ou seja, muitos dos jogadores estavam recebendo para jogar e, como o clube sempre teve como objetivo principal promover o esporte amador, a diretoria, sob a presidência do Dr. Antonio Prado Junior, resolveu encerrar suas atividades de futebol de campo junto à Federação. A última partida de futebol disputada pelo Paulistano foi em 15 de dezembro de 1929 contra o Antarctica Futebol Clube". 
futebol da Capital, este mantinha relações com interesse de benefícios clubísticos. Jogando com clubes do interior quatro pontos eram garantidos pelo clube da Capital, quando mantinha relações com dirigentes do interior. Como recompensa, o convite para participar de festas, reuniões e interagir em meio à "burguesia" paulistana, o que assinalava certa ascensão do dirigente do interior (ROCHA NETTO, 2000).

A formação popular de times e agremiações no início dos primeiros anos do século XX verifica-se a ausência do Estado, isso porque o tecido burocrático estatal não estava presente. Erigir políticas públicas e legislação na possibilidade de disciplinar a criação e a formação de clubes esportivos, recreativos e de lazer passou a ser cogitado na década de 1930, mas essas ações só foram efetivadas pelas ações governamentais em 1940. Assim, longe do poder burocrático, livre para se organizar, a institucionalização de clubes populares ocorreu num período fértil para o desenvolvimento do futebol.

Essa "formação popular" da qual descendem muitos clubes paulistas foi a propulsora do futebol interiorano bandeirante, tendo atualmente faces que ainda se encontram arraigadas e manifestam distinções entre um clube e outro. Podem ser observadas distinções nos clubes populares, estando entre essas: a popularidade do torcedor/simpatizante do clube, a tradição burocrática clubística, as tradições populares presentes no contexto maior do clube e autoridade carismática do dirigente.

Essas distinções trazem muito da formação inicial do clube. A formação popular aponta tradição de grupos de torcedores do clube. Tal fato pode ser identificado nos clubes de raízes populares ou não, onde as identificações dos torcedores com o clube são tradições que remontam a décadas que socialmente podem ser atribuídas à continuidade como uma descendência familiar. No início, era o gosto de jogar bola, depois passou à admiração pelo clube, pelas cores, pelos símbolos, com uma paixão maior. O próprio praticante ou associado se envolvia cada vez mais com o clube que se tornava à extensão de sua própria vida social.

Outra distinção decorre das lentas transformações existentes nos clubes de características populares. A mudança de idéias, de trabalho e de novos paradigmas administrativos e sociais é lenta e toda transformação percorre um caminho de difícil reversão do que está posto e enraizado na constelação dos poderes dos dirigentes. Isso faz repercutir uma oposição às novas legislações e modernização de administração 
clubística e os dirigentes teimam em julgar que são perigosas para seus feudos/clubes. Nessa mesma abordagem, a presença de dirigentes folclóricos é uma identificação dos clubes populares, onde a presença do "dono" do time, do clube, é "figura" marcante no cenário do contexto do futebol. Essa "autoridade" encontra-se em Weber, que trata de uma posição consciente, e a "autoridade" é considerada legítima e seus seguidores estabelecem, lealdade, legitimidade e é pessoal. Não é a estrutura burocrática e administrativa do clube que chancela as vitórias, mas o presidente "tal" é quem comanda com seu carisma a vida da equipe. ${ }^{4}$

Outra característica trata das tradições que permeiam os clubes de formação popular. Assim, o Corinthians tem São Jorge como santo protetor; o XV de Piracicaba, a figura do Nhô-Quim, que marca a identidade típica da região piracicabana; e a Ponte Preta coloca como símbolo a macaca, devido a seu jeito simpático e alegre, introduzindo um símbolo feminino no futebol. É entre essas identificações que o popular aparece de forma mais latente e aparente nos clubes populares. O antropólogo Ballandier (1997) indica que a tradição para se manter viva é necessário que tenha um símbolo pelo qual o homem possa manter seu campo subjetivo. É uma insígnia, um totem, uma flâmula que mantém vivo o campo subjetivo - que une, que cria relações gratuitas e mantém, sobretudo, um clube como uma continuidade de parentesco.

Mostrando a força do futebol do interior de São Paulo, a formação dos clubes aponta as bases populares. Esse cenário popular pode ser visto na fundação dos principais clubes paulistas do interior, entre esses, em 1900, A. A. Ponte Preta, de Campinas; em 1906, Associação Atlética Internacional de Bebedouro e Clube Atlético Pirassununguense (Pirassununga); em 1909, Rio Claro Futebol Clube e Paulista F.C (Jundiaí); 1910, Associação Esportiva Velo Clube Rioclarense (Rio Claro); em 1910, Esporte Clube Noroeste (antigo B.A.C., Bauru) e Guarani Futebol Clube (Campinas); em 1911, Jaboticabal Atlético e Comercial Futebol Clube (Ribeirão Preto); 1912, Associação Atlética Francana; e em 1913, Rio Branco Esporte Clube (Americana),

\footnotetext{
${ }^{4} \mathrm{O}$ dirigente Alfredo Metidieri é um exemplo típico do administrador que rege pelo poder do carisma e da pessoalidade. Metidieri foi presidente do E. C. São Bento de 1954 a 1981. De 1976 a 1978, foi presidente da FPF, quando o seu clube, o São Bento, obteve as suas maiores conquistas. Ao deixar o clube, a agremiação foi rebaixada pelas divisões inferiores do campeonato paulista (ROCHA NETTO, 2000).
} 
Esporte Clube São Bento (Sorocaba), Associação Atlética Internacional (Limeira) e Esporte Clube XV de Novembro de Piracicaba .

Praticamente, todos os clubes do interior, em sua formação, são oriundos de grupos/estratos populares, como operários que formavam equipes rivais, ou permitiam a fusão de equipes, fortalecendo-se para o embate com outras da mesma região. Exemplo disso são o XV de Piracicaba, a Ponte Preta e o Botafogo de Ribeirão Preto, este último formado por ferroviários.

No interior de São Paulo, já na segunda década do século XX, era possível identificar regiões de certo desenvolvimento do futebol. Podemos determinar duas faces distintas desse fenômeno. A primeira relacionada com as Escolas Agrícolas da Capital, de onde os estudantes retornavam para o interior com gosto pelo futebol, introduzindo e formando equipes em seus respectivos municípios. Em grande medida, esse foi o caso das equipes de Campinas, Bauru, Piracicaba, Jundiaí, Limeira, Sorocaba e de outras cidades fora desse eixo.

A segunda face refere-se às regiões servidas por estradas de ferro, datando da época de pujança da cultura cafeeira, ligando o interior paulista à cidade portuária de Santos, ou a Capital às regiões atingidas pelas Cias. Mogiana, Sorocabana, Paulista, Ituana e Linha Noroeste e também a região de Ribeirão Preto, além de Rio Claro, onde se formaram equipes que traz em seu nome a identificação da Cia. Férrea: Ferroviário Ituano, Noroeste de Bauru e Ferroviária de Araraquara, sendo a equipe do Botafogo de Ribeirão Preto formada pela fusão de dois times pertencentes aos trabalhadores na linha férrea, em 1918.5

Embora seja pouco mencionado nas literaturas, o futebol no interior de São Paulo tem o privilégio de contar com o segundo clube mais velho de futebol do Brasil, a A. A. Ponte Preta, além de outros que, ao longo de sua história, contabilizam muitas vitórias sobre os clubes da Capital. No entanto, para os nossos objetivos, entendemos

\footnotetext{
${ }^{5}$ Em 1918, na tentativa de fundir três equipes, o União Paulistano, o Ideal F. C. e o Tiberense, seus dirigentes, discutindo no Bar do Piranha, não chegavam a um acordo, quando um deles disse que teria que sair um nome logo, senão "botava fogo" em tudo o que estava escrito. O nome ficou "Botafogo".
} 
ser necessário apontar a formação histórica de clubes do interior e os atores/jogadores oriundos das classes populares.

Rosenfeld (1974) já revelava, em seu artigo O futebol no Brasil, que clubes "grandes" passaram a hostilizar a equipe do Paulistano por esta equipe ter galgado à primeira divisão com jogadores "de outras zonas", entendendo-se essas zonas como subúrbios. ${ }^{6}$ Essa motivação nasceu não porque o clube tenha desistido de sua "aristocracia", mas como resultado do rebaixamento do primeiro nível. Na procura de novos talentos, já no início dos anos 20, a maior parte dos times de elite, incluindo aí o Paulistano, começou a contratar jogadores que uma década antes não teriam sido admitidos.

Antunes (1996), em estudo sobre o futebol e seu processo de profissionalização na empresa canadense The São Paulo Tramway, Light \& Power Co. Ltda. indica que, no decorrer das primeiras décadas do século XX, a empresa apoiava a formação de equipes de futebol entre seus funcionários. Apresentando na época padrões modernos de gerenciamento, a Light \& Power possuía diversos grupos esportivos em suas empresas espalhadas pelo interior. Conforme Decca (1987), o quadro de funcionários da empresa, cerca de 7000 trabalhadores, contava com muita "gente comum" do interior, o que revelaria, já no princípio do século XX, a popularidade do futebol, assim como a organização popular de sua prática. Vale aqui ressaltar que na esfera pública a cultura popular muitas vezes reflete os comportamentos e atitudes das elites, logo isso não implica que a popularização e a popularidade do futebol, no início do século XX, tenha repercutido como um avanço de uma classe oposta à burguesia da época. Aliás, o futebol podia servir como instrumento de cooptação pelo poder estatal, contrariando o que determinadas literaturas apregoam.

\footnotetext{
${ }^{6}$ Segundo Vogel, “[...].nas primeiras décadas [do século XX], foi praticado [o futebol] quase que exclusivamente por jovens da elite social do Rio e de São Paulo. Sua popularização vem da década de 30" (1982, p. 94). A Folha de São Paulo, em artigo de 16 de janeiro de 1994, coloca 1918 como o ano em que "os negros foram aceitos no futebol [...]. Só em 1918, por pressões da imprensa, a Federação Brasileira de Sports autorizou formalmente os clubes e entidades regionais a aceitarem inscrições".
} 
Decca, ao apontar a política dos governos estaduais no início do século XX, principalmente nas grandes metrópoles, indica a sustentação do futebol instrumentalizado como possibilidade de "regeneração do homem urbano". Essa possibilidade não compreendia somente a política de erradicação das doenças ou epidemias da época: era preciso que o Estado atribua à turba urbana, em seu tempo livre, algum lazer que pudesse repercutir na produção, nos turnos de trabalho. O projeto de reordenamento arquitetônico dos espaços urbanos tratou de criar elementos capazes de anunciar e incorporar à população novos hábitos, costumes e valores urbanos, exigidos numa metrópole. São Paulo, como outras grandes cidades, obedeceu a essa nova ordem, constituindo vilas e regiões onde se revelava a hierarquia social e cultural: Vila dos Italianos, no Bixiga, Vila dos Orientais, na Liberdade; dos Portugueses - cada qual em sua ordem. Assim, em São Paulo, o Estado construiu campos de futebol, dotando a várzea e os bairros periféricos de estruturas pelas quais os diversos grupos urbanos pudessem tomar gosto pelo esporte.

Apoiadas no discurso higienista, outras instituições vieram a incorporar o lazer como fonte de manutenção de um estado moral e mais produtivo para a classe operária. A Igreja oferecia o seu lazer nas quermesses e procissões, sendo alvo da oposição dos anarcossindicalistas, que viam no lazer instituído uma forma de "preparação do corpo do proletário" unicamente para fazê-lo produzir mais no trabalho. Quanto às indústrias, trataram de construir campos de futebol próximos às vilas operárias, onde promoviam os jogos logo após as atividades religiosas, aos domingos.

A construção de campos de futebol não ficou restrita somente às grandes metrópoles. No interior de São Paulo, cidades como Campinas, Jundiaí e Piracicaba adotaram essa mesma política, tendo, inclusive, clubes que em sua maioria eram compostos por "gente da cidade", os quais vieram a formar as equipes profissionais desses municípios (Arquivo Rocha Netto). Entre as cidades interioranas do Estado de São Paulo, Piracicaba e Campinas representam um cenário típico, em que a formação das equipes era basicamente obra de jovens estudantes da classe média.

O processo de desenvolvimento, de participação e de democratização do futebol brasileiro em diferentes regiões do País ocorreu mostrando cenários diferentes, devido às condições de cada local. Não foi um processo, um projeto pensado para tal fim. 
Resumidas a pequenos grupos de estudantes, as primeiras equipes de futebol em Campinas, Jundiaí, Limeira e Piracicaba tiveram necessidade de se abrir à participação de grupos da zona rural e vilas periféricas, ocorrendo assim à entrada das camadas populares no futebol. Na cidade, na vida urbana, a vigilância sobre "quem é quem" era preocupação intensa, e as proibições de classe e de etnia cultural recebiam atenção de clubes e de grupos sociais. Em Campinas, conforme Santos Neto (2000), o futebol era alvo dessa preocupação: “com quem jogar" e "com quem andar”. Mas não foi possível frear os símbolos das distinções sociais no futebol: a possibilidade de identificar o popular no futebol na formação de um time como A.A. Ponte Preta, é visível, pois o clube nasceu com o objetivo de formar meninos e jovens sem distinção social e de raça (SANTOS NETO, 2000, p. 24) pois desde sua fase inicial, o elenco titular era composto, na sua maioria, por jovens pertencentes às classes populares.

A fase inicial do E. C. XV de Novembro se assemelha às demais equipes da região. No entanto, na equipe formada por jovens pertencentes às camadas populares, esse status não durou muito. Formada por fusões das equipes do XII de Outubro e pelo Vergueirense, ambas pertencentes a duas famílias, tinham como objetivo enfrentar os alunos da Escola Agrícola, hoje Escola Superior de Agricultura Luiz de Queiroz (ESALQ). Diversas fusões entre os times de futebol da cidade foram feitas com esse intento, mas sempre infrutíferas, até que, em outubro de 1913, ambas reunidas, discutia-se que nome dariam à nova equipe. Sem nenhum acordo, o Sr. Cap. Wingeter foi chamado a opinar. Como se aproximava a data de 15 de novembro, o time foi batizado com esse nome, com ordem do Sr. Capitão, que mais tarde seria presidente do clube.

Como o Capitão Wingeter era proprietário do local onde a equipe do XV de Novembro jogava, a escalação era deliberação sua, o que acrescentava mais poder ao primeiro presidente do clube, pois, sendo dono das bolas encomendadas em São Paulo, e por pertencer à elite da cidade, o Capitão passou a chamar os estudantes da Escola Agrícola para sua equipe. Enquanto as demais equipes da região tinham em seu elenco a juventude da população operária da época, o XV de Piracicaba se elitizava cada vez mais, vindo a abrir-se para as camadas populares no fim dos anos 20 , quando percebeu que, com a inclusão dos jovens pertencentes às camadas populares, poderia obter êxitos 
em suas disputas. Durante o período da elitização, o XV de Piracicaba jogou com diversos times da Capital, entre esses, o Paulistano e, de outra forma, negou-se a jogar com os clubes da região, quando convidado. A presidência temia e entendia que poderia haver violência, uma vez que o "refinamento" dos jogadores do XV de Piracicaba não convinha com o tipo de jogo do time que emitia o convite para enfrentá-lo. Quanto à forma de conduzir o clube, que em 1914 já contava com uma equipe feminina de basquete, o presidente usualmente seria um provedor que patrocinasse a equipe em suas viagens, uniformes e bolas e que mantivesse os locais de treinamento. Tal fato perdurou até meados de 1970, quando a cidade ainda outorgava a presidência do Clube aos nomes "ilustres" da cidade.

As primeiras equipes tinham como dono aquele que pudesse comprar na Capital, ou importar, o material e os instrumentos necessários à prática do futebol. Desse modo, a formação era basicamente de estudantes. Outras equipes do interior paulista também se constituíram de jovens estudantes, principalmente nos municípios de Campinas, Americana, Jundiaí, São Carlos e Ribeirão Preto. Essas equipes vieram a aceitar a entrada de alguns negros, operários, jogadores habilidosos, conseguindo, inclusive, importantes vitórias em disputas com os clubes da Capital. Contudo, a entrada desses jogadores não foi fácil de assimilar e aceitar.

$\mathrm{Na}$ mesma região, vemos que a formação do segundo clube de futebol mais antigo do Brasil, a A. A. Ponte Preta, registra em sua história uma sólida identificação popular. A Cia Paulista de Estradas de Ferro inaugurou, em 11 de agosto de 1872, a linha Campinas-Jundiaí, tornando-se um pólo de desenvolvimento da cidade. Um contingente de trabalhadores de diferentes qualificações, brasileiros e estrangeiros, passou a residir em Campinas, trazendo a experiência cultural de várias regiões brasileiras e européias. Até os anos finais do século XIX, Campinas não contava com associações, tendo o futebol como objetivo único. A prática do exercício físico, a ginástica, era típica da colônia alemã; em 1885, foi fundada a Sociedade Allemã de Gymnastica Infantil e, em 1890, Campinas vê nascer outra entidade semelhante, a Sociedade Gymnastica Allemã.

A introdução do futebol em Campinas pode ser identificada por três caminhos: o primeiro, o das ferrovias e seus funcionários estrangeiros e brasileiros; o segundo, nos 
estabelecimentos de ensino (colégios); e o terceiro com a influência das colônias de imigrantes europeus, destacando-se os alemães. A fundação da Ponte Preta, em 11 de agosto de 1900, deu-se em homenagem ao nascimento da ferrovia; a ponte preta dá nome ao bairro e o clube recebeu esse nome, com formação operária e de trabalhadores, não restringindo a participação étnica.

Em entrevista com o Sr. Benedito Halita, 50 anos trabalhando na A. A. Ponte Preta, ele nos diz que

[...] tudo que aconteceu no time é obra dos moradores do bairro. Tudo correu em torno da Ponte Preta. Quando havia festas, as mesmas pessoas que tocavam o time é que faziam a festa. Se tinha uma comemoração religiosa ou da pátria, era o mesmo grupo que trabalhava pra acontecer. A Ponte foi muito popular. Saiba que até os tijolos para construção do campo da Ponte foi doação de cada morador do bairro. Saíram diversos caminhões pra rua e uma multidão de pessoas pedindo tijolos nas casas, no comércio para erguer o nosso estádio. É essa a diferença de outros times, por isso não tem no Brasil nenhum time do interior que tem uma torcida como a Ponte Preta.

Para Santos Neto (2000), a formação da Ponte Preta se fez como que houvesse uma comunidade de sentimentos mútuos, existindo uma ligação perpétua. Isso fez com que o clube representasse um gosto popular, em que faces populares nitidamente podem ser identificadas nos enredamentos sociais. É desse encontro continuum negociado entre o geral e o particular que se manifesta uma das características mais marcantes na vida urbana. Quanto maior e abrangente uma instituição que favorece contatos, trocas de influências e interesses, entrecortados por faces culturais, as singularidades dessas trocas sociais ampliam os horizontes para o fortalecimento das realizações das experiências humanas e, como vimos, as relações mútuas nos espaços do futebol favoreceram essas possibilidades. 


\section{Considerações Finais}

O estudo que desloca a atenção para o futebol do interior do Estado, logra êxito, pois abre possibilidades de novos olhares e reflexões. Aqui, o êxito do estudo nos levou a estudar novos cenários, sendo esse a organização de trabalhadores e operários que fundaram os primeiros clubes interioranos de futebol do Estado de São Paulo. O êxito se encontra no momento em que identificamos, no seio do futebol, a possibilidade de seus agentes organizarem-se nas diversas estruturas sociais e interagirem em grupo garantindo a possibilidade de sua continuidade. Se Ballandier (1997) possibilita entender que a continuidade da tradição só é possível no interior de alguma estrutura da sociedade, futebol configurou esse espaço, acolhendo o cotidiano de seus atores, transformando-o, apropriando-se e criando novos contornos, mantendo a tradição coletiva. Mas há uma outra configuração na qual a coletividade não significa caminhos livres, autônomos e emancipatórios. Há necessidade criar novos códigos, pois as estruturas sociais entrecortadas pela ocupação dos espaços revezam poderes e, que no decorrer do processo, as relações se tornam oram paralelas ora simétricas. É nesse momento que as organizações sociais populares, no início do s;éculo XX nos forneceu como exemplo: a possibilidade de continuidade de uma organização foi possível quando se estabeleceu um campo de idéias, mantendo um campo simbólico que unia e estreitavam relações mútuas e sociais.

Ao conquistarem os espaços políticos das instituições burocráticas que figuram na organização do futebol paulista, os dirigentes dos clubes do interior bandeirante entenderam que só seria possível a manutenção do status clubístico na soma dos diversos grupos que compunham a força da sociedade local. Enquanto na Capital os grupos figuravam pela distinção social e étnica, o interior se distinguia pela absorção dos diversos estratos sociais. 


\begin{abstract}
This is a study on the foundation and constitution of clubs inland São Paulo, restricting its analyses to A. A. Ponte Preta, from Campinas, and E. C. XV de Novembro, from Piracicaba. It reveals the workers' organization, the symbol building and the clubs' administration, composing the typical view of São Paulo inland clubs that are still present in contemporary soccer. It shows the relations among club directors from inland and capital and the bureaucratic and individual interests that surrounded these relations. The study considers that the clubs maintenance depends on the continuity of the relations that promote the social entanglements and that, historically, the clubs formation occurred within the organization of several social and ethnics stratums.
\end{abstract}

Key-Words: Paulist soccer; Organization; Social relations.

\title{
Referências Bibliográficas
}

ANTUNES, F. M. R. F. O futebol na light \& power de São Paulo. Revista Pesquisa de Campo, Rio de Janeiro, n. 3/4, 1996.

BALLANDIER. G. O contorno: poder e modernidade. Rio de Janeiro: Bertrand Brasil, 1997.

MÁRIO FILHO. O negro no futebol brasileiro. Rio de Janeiro, 1964.

MAZZONI, T. Problemas e aspectos do nosso futebol. São Paulo: Olimpicus, 1939.

RIGO, L. C. Memórias de um futebol de fronteiras. 2001. Tese (Doutorado em Educação Física) - Faculdade de Educação Física, Universidade Estadual de Campinas, Campinas, 2001.

ROSENFELD, A. O futebol no Brasil. Revista Argumento, São Paulo, ano 1, n. 4, fev. 1974.

ROCHA NETTO, D. Arquivo histórico do futebol paulista. Piracicaba, 2000. (Arquivo pessoal).

SANTOS NETO, J. M. O início de uma paixão: a fundação e os primeiros anos da Associação Atlética Ponte Preta. Campinas: Komedi, 2000. 